\title{
Design and characterization of self-sensing steel fiber reinforced concrete
}

\author{
Teuku Ferdiansyah ${ }^{1 *}$, Anaclet Turatsinze ${ }^{1}$, Jean-Paul Balayssac ${ }^{1}$ \\ ${ }^{1}$ LMDC, INSA/UPS Génie Civil, 135 Avenue de Rangueil, 31077 Toulouse cedex 04 France
}

\begin{abstract}
The purpose of this communication is to develop a self-sensing cement composite capable of detecting stress variation in concrete by monitoring its electrical property. The relationship between the electrical properties, i.e. electrical resistance of steel fiber reinforced concrete, and stress under loading as part of self-sensing study is presented in here. Amorphous metallic fibers (AMF) with two different lengths i.e. $10 \mathrm{~mm}$ and $30 \mathrm{~mm}$ are used as concrete reinforcement at a content of $40 \mathrm{~kg} / \mathrm{m}^{3}$. A water to cement ratio of 0.39 was adopted for the mix proportions. Natural fine and coarse siliceous aggregates were used for this research. Superplasticizer was used to achieve the target of workability. The two-probe method is used for measuring electrical properties on cylinder specimens with diameter $100 \mathrm{~mm}$ and height $200 \mathrm{~mm}$. The influence of different parameters such as fiber length, frequency of power input, maximum stress and variation of potential input on the sensitivity of the sensing are investigated. The results indicate that the electrical resistance of the concrete decreases reversibly during loading and increases reversibly during unloading. Good sensitivity obtained for the mix using $30 \mathrm{~mm}$ AMF length indicates that the addition of this type of fiber into concrete can be suitable to produce a self-sensing cement composite.
\end{abstract}

\section{Introduction}

Self-sensing concrete also described as smart concrete material was invented in 1993 by Prof. D Chung, University of Buffalo, US. Chung defined the self-sensing function by reference to concrete as the ability of the material to provide an electrical response to a strain or stress stimulus [1]. The self-sensing concrete concept overcomes disadvantages of embedded sensor such as high cost, limited investigated area, non-composites effect, poor durability etc. The change of concrete properties could be due to external loading or to an internal reaction (swelling reaction like ASR for instance, Internal Sulphate Attack....). The accuracy of the change of electrical resistivity depends a lot of concrete ability to deliver the signal to the surface of concrete constantly and continuously. Modification of the concrete admixtures can be a solution to improve the self-sensitivity of such cement-based material. The concrete sensing is related to the change of electrical resistivity as the effect of any change of concrete properties. A more conductive concrete has a better self-sensing ability compared to a less conductive concrete. In general, there are two types of electrical conduction in concrete composites, i.e. ionic conduction and electronic conduction. Ionic conduction refers to the ion movements through pore solution as the results of cement paste hydration. Meanwhile, electronic conduction is linked to ability of the medium to transport the electrons via conductive materials such as carbon fiber, steel fibers or rebars. The addition of steel fibers into the concrete as the media to transfer electrons is expected to improve the conductivity of concrete and in the same time to increase the self-sensing ability of concrete. The electrical properties of fiber concrete strongly depend on fiber-cement matrix contact. The better fiber-cement matrix bond leads to the concrete with better conductivity. Nevertheless, when fiber pull-out along with widening crack, the fiber-cement matrix contact resistivity is increasing and make the concrete less conductive [2].

Previous researches use different kind of fibers to study the self-sensing ability of concrete composites, such as Carbon Short Fiber [3], [4], Carbon Micro Fiber [1], [5]-[7], carbon nano fibers[8]-[11], steel fiber [12]-[14].

In this contribution, design of self-sensing steel reinforced is a series of experimental operations which includes concrete mix proportioning as well as mechanical compression tests to evaluate the self-sensing capacity of the composite. The self-sensing properties of steel fiber reinforced concrete are investigated by using electrical resistivity measurement with a two-electrodes method. Effects of fiber length, potential input, frequency and of level of loading are compared. 


\section{Experimental Program}

\subsection{Material}

The test specimens were made using the following materials: Ordinary Portland Cement, tap water, round siliceous aggregates for gravel and sand, a superplasticizer and Amorphous Metallic Fiber (AMF) produced by Saint Gobain SEVA in France.

The conventional steel fibres are made from long, fine wires exhibiting a crystalline structure with preferential directions giving the metal anisotropic properties. Meanwhile, AMF are manufactured by hyperquenching with a cooling rate above $10^{6} \mathrm{~K} / \mathrm{s}$. The melting temperature is therefore passed so fast that the atoms do not have time to form a crystalline system: a supercooled liquid is obtained, which solidifies into an amorphous state where atoms have the disordered isotropic organization of a liquid. The presence of chromium and the isotropy ensure corrosion resistance and resistance to aggressive environments that are higher than those of conventional steel fibres.

AMFs are very thin $(24$ or $29 \mu \mathrm{m})$ flat ribbons and the number of fibres per volume unit is higher than for conventional steel fibres. The resulting high specific area of AMFs leads to a very strong bond between the AMFs and the cement matrix. AMFs exhibit perfect elasticbrittle behaviour with little or no plasticity. AMFs are especially convenient in the most aggressive environments and are suitable for sanitation networks, road buffers, shotcrete, sealing mortars, technical slabs, and prefabricated products such as nuclear waste containers, etc.

\subsection{Sample preparation}

As shown in Table 1, the concrete mixture with 0.39 water to cement ratio and an expected compressive strength of $50 \mathrm{MPa}$ was used to cast specimens. The proportions of coarse aggregates and fine aggregates were 57:43. The fiber was employed at a volume fraction of $0.56 \%$ (40 $\mathrm{kg} / \mathrm{m}^{3}$ ) and divided into two types: i.e. $10 \mathrm{~mm}$ length with aspect ratio 56 and $30 \mathrm{~mm}$ length with aspect ratio 120 . Cylinders with diameter $100 \mathrm{~mm}$ and length $200 \mathrm{~mm}$ were prepared and cured in controlled atmosphere $\left(20^{\circ} \mathrm{C}, 90 \%\right.$ $\mathrm{RH})$. The specimens were demoulded after 24 hours and stored in water until the testing.

Table 1 Mixture proportions

\begin{tabular}{|l|r|}
\hline \multicolumn{1}{|c|}{ Material } & Quantity (Kg/m3) \\
\hline Cement (CEM I 52.5 R) & 380 \\
Sand & 1031 \\
Coarse Aggregate & 784 \\
Efficient Water & 146.5 \\
Superplasticizer & 7.6 \\
Amorphous Metallic Fibres & 40 \\
W/C & 0.39 \\
\hline
\end{tabular}

\subsection{Test method}

The two-electrodes technique was developed for electrical resistance measurements. The electrodes are made by a copper ring attached to the surface of the concrete sample, as seen in Figure 1. Conductive paint was applied between copper ring and concrete surface to increase the contact between electrode and concrete. The specific AC voltage value was applied to the electrodes using a function generator. AC electric source was used to avoid the polarization effect which normally happens with DC measurement. A digital multimeter recorded the current values of the sample subjected to alternating current (AC) at specific frequencies and voltages. During the test, digital multimeter was connected to a computer to collect the real display of measurement (Figure 2).

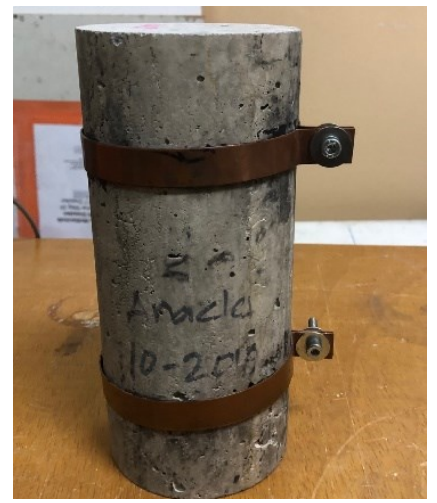

Fig. 1. Arrangement of electrodes

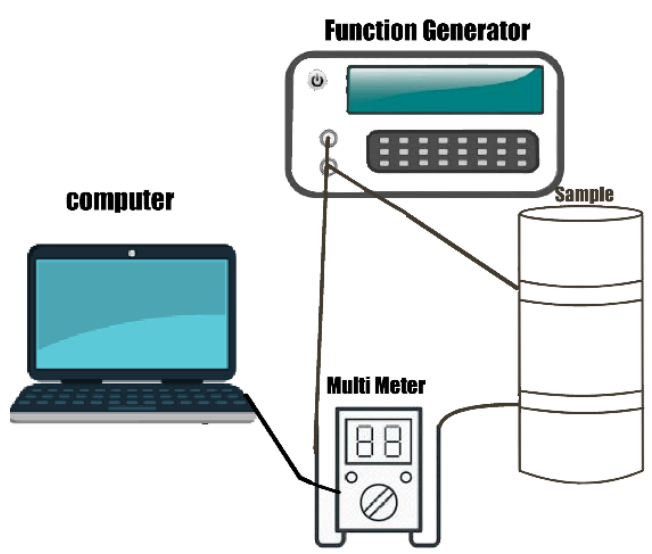

Fig. 2. Schematic display of testing setup

The configuration of testing depends on the objectives. To access the fiber length effect and maximum stress effect, the frequency was set to $50 \mathrm{~Hz}$ and the voltage to $20 \mathrm{~V}$. For the test of voltage input effect, the frequency was set to $50 \mathrm{~Hz}$ and the voltages were set to $10 \mathrm{~V}$ and $20 \mathrm{~V}$. Meanwhile for a test of frequency effect, the frequencies were set to $50 \mathrm{~Hz}$ and $500 \mathrm{~Hz}$ with fixed voltage input of $20 \mathrm{~V}$. Three cyclic loadings under compression with loading rate $0.5 \mathrm{MPa} / \mathrm{sec}$ were applied to the sample within a range from $30 \mathrm{kN}$ to $150 \mathrm{kN}$ and from $30 \mathrm{kN}$ to $300 \mathrm{kN}$.

The electrical resistance values of the sample were calculated using Ohm's law. The sensitivity level was 
measured by means of the Fractional Change in electrical Resistance (FCR) in percentage. FCR can be expressed as

$$
F C R(\%)=\left(\frac{R t-R o}{R o}\right) \times 100
$$

Where $R_{0}$ is the initial electrical resistance of the unloaded specimen, and $R_{t}$ is the electrical resistance at a given time.

\section{Results}

\subsection{Effect of Fiber Length}

The effect of fiber length on fractional change of electrical resistance under repeated loading is shown on Figures 3 and 4 . Figure 3 shows the fractional changes in electrical resistance for fiber length $10 \mathrm{~mm}$, meanwhile Figure 4 shows results for fiber length $30 \mathrm{~mm}$.

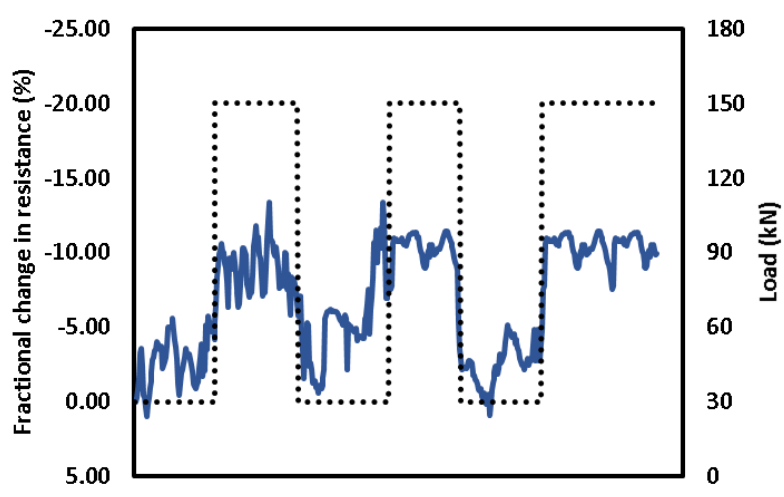

Fig. 3. Fractional change in electrical resistance (continuous line: under repeated loading (dot line) using fiber length of 10 $\mathrm{mm}$ with applied voltage of $20 \mathrm{~V}$ and frequency of $50 \mathrm{~Hz}$.

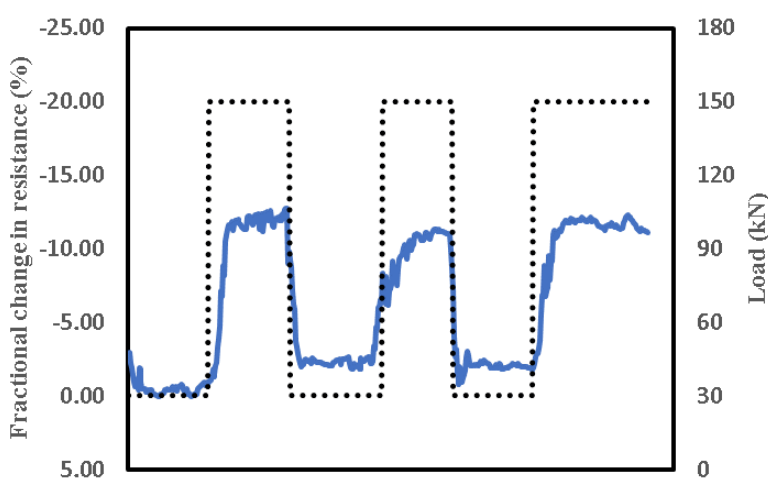

Fig. 4. Fractional change in electrical resistance (continuous line) under repeated loading (dot line) using fiber length of 30 $\mathrm{mm}$ with applied voltage of $20 \mathrm{~V}$ and frequency of $50 \mathrm{~Hz}$.

It can be seen from both figures that the electrical resistance decreases with loading and increases during unloading. The changes of electrical resistance of steel fiber reinforced concrete because of loading variation can be interpreted as the consequence of the change of contact between fiber and cement paste [15]. In general, the level of sensitivity for both lengths for a compressive load between $30 \mathrm{kN}$ to $150 \mathrm{kN}$ is almost the same, around $12 \%$. However, there are two significant differences between fiber length of $10 \mathrm{~mm}$ and the one of $30 \mathrm{~mm}$. First, the response by the mixture with a fiber length of $30 \mathrm{~mm}$ is more stable compared to the fiber length of $10 \mathrm{~mm}$. Secondly, $30 \mathrm{~mm}$ length fiber provides a good repeatability response for load variation for each cycle. These good performances of the mixture with longer fiber length is due to the fact that the longer fiber increases the bond strength with cement paste and finally increases the conduction of the cement paste [16]. In other words, concrete reinforced by fiber with longer length gives more interesting electrical properties.

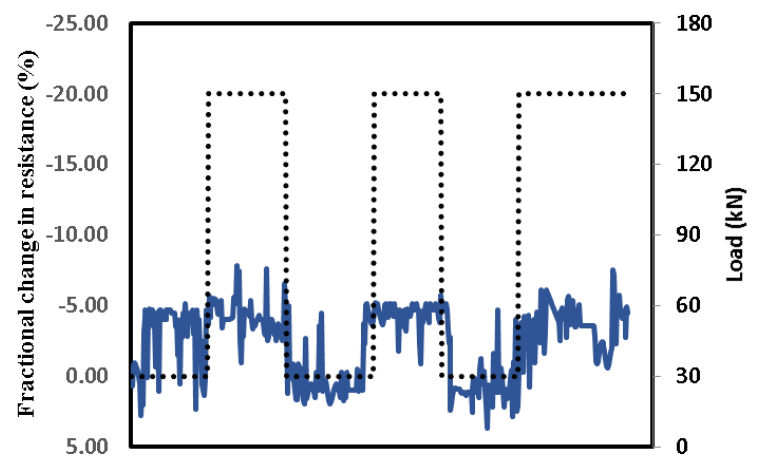

Fig. 5. Fractional change in electrical resistance (continuous line) under repeated loading (dot line) using fiber length of 30 $\mathrm{mm}$ with applied voltage of $10 \mathrm{~V}$ and frequency of $50 \mathrm{~Hz}$.

\subsection{Effect of Potential Input}

The test used two different values of AC potential input, i.e. $20 \mathrm{~V}$ (Figure 4) and $10 \mathrm{~V}$ (Figure 5). The concrete is the one with fiber length of $30 \mathrm{~mm}$ and the frequency is $50 \mathrm{~Hz}$. The three cycles of compressive load between 30 $\mathrm{kN}$ to maximum $150 \mathrm{kN}$ were applied to the sample. It can be seen from Figure 4 and Figure 5 that FCR decreases when the potential input decreases. Figure 4 shows that the FCR for the test using $20 \mathrm{~V}$ is up to $12 \%$, meanwhile Figure 5 shows the FCR with potential of $10 \mathrm{~V}$ is less than $6 \%$. It is also noted, that the electrical resistance did not exhibit significant decrease with increasing of loading. Referring to Ohm's law, applying low voltage to concrete sample, for which resistance value is constant (before loading), will result in low current. Therefore, the variation of low current because of loading changes was insignificant. Since electrical resistance is calculated from the variation of current, then the FCR is difficult to detect when using low voltage input as effect of loading variation. In his study on the detection of damage by using self-sensing concepts, Chung specified that the changes of small resistance value is difficult to be measured [17]. However, the study by Han et al. shows for carbon nanotube concrete composites that using low-amplitude of AC voltage is helpful for improving the sensitivity of composites to detect the effect of loading variation [18]. 


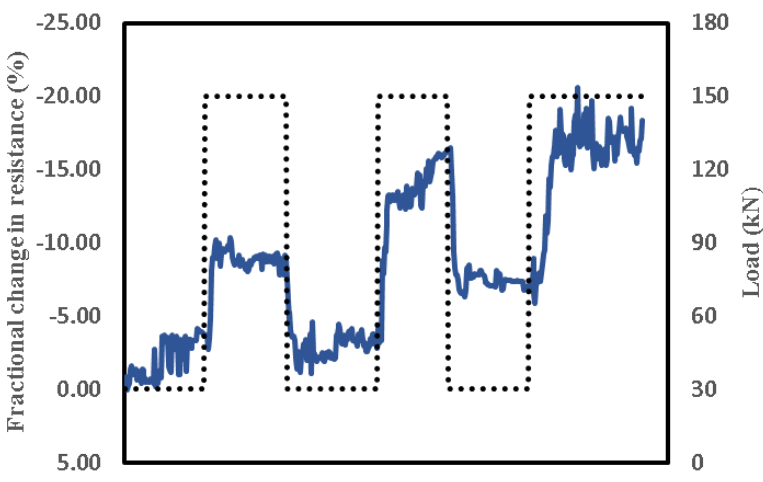

Fig. 6. Fractional change in electrical resistance (continuous line) under repeated loading (dot line) using fiber length of 30 mm with applied voltage of $20 \mathrm{~V}$ and frequency of $500 \mathrm{~Hz}$.

\subsection{Effect of frequency}

The frequency value is an important parameter to be considered when AC source is used. Frequency has a different effect on capacitive reactance and inductance reactance. High frequency produces lower capacitive reactance and contrary, high frequency lead to higher inductance reactance. The effect of frequency i.e. $50 \mathrm{~Hz}$ and $500 \mathrm{~Hz}$ on steel fiber reinforced concrete is presented in Figure 4 and Figure 6 respectively. The test shows the effect of frequency on FCR for the three cycles of loading between $30 \mathrm{kN}$ and $150 \mathrm{kN}$ with the potential input of 20 V.

The variation of frequency produces different variations of FCR as the response to repeated loading. For a test with high frequency, i.e. $500 \mathrm{~Hz}$, each cycle gives a different value of FCR. The FCR is between $0 \%-11 \%$, $2 \%-16 \%, 7 \%-19 \%$ for $1^{\text {st }}$ cycle, $2^{\text {nd }}$ cycle and $3^{\text {rd }}$ cycle respectively. While the test produces high sensitivity for each cycle, it also shows the lack of repeatability. The FCR at initial loading and the one at maximum loading for each cycle are not the same. It seems that the electrical resistance increases with time. This is probably due to the effect of the change in capacitance or in inductance values of concrete because the changes of frequency. It is believed that these changes of capacitance and of inductance lead to the changes of sensing characteristic of concrete composites [19].

\subsection{Effect of level of load variation}

Figure 7 illustrates the variation of compressive load and FCR with time during 3 cycles of compressive loading with amplitude of $30 \mathrm{kN}$ to $300 \mathrm{kN}$. For this specimen, compressive load at $300 \mathrm{kN}$ and $150 \mathrm{kN}$ is approximately $76 \%$ and $38 \%$ of compressive strength of the concrete. The figure shows that the FCR value from $30 \mathrm{kN}$ to 300 $\mathrm{kN}$ is $24 \%$. As a comparison, the FCR from $30 \mathrm{kN}$ to 150 $\mathrm{kN}$ with same fiber length i.e. $30 \mathrm{~mm}$ is $12 \%$ (Figure 4 ). This means that fiber length of $30 \mathrm{~mm}$ is not only able to produce a good sensing response on low compressive loading (36\% of concrete strength) but also on high compressive loading (76\% of concrete strength). As it can be seen in that figure, the electrical resistance of the specimen decreases linearly during loading and increases linearly during unloading. However, the results also suggest an instability of sensitivity value $(19 \%-24 \%)$ at maximum loading and (0\%-5\%) at initial loading. This is because at such high level of loading the micro-cracking occurs which permanently changes the electrical properties of concrete composites [20]. The study also showed the instability of electrical resistance response at initial and maximum loading. It is maybe due to the mechanism of the compressive machine itself. In order to maintain stress at specific value, the machine needs to adjusted the pressure. The electrical resistance of concrete was response to the adjusted pressure and produce the instability value.

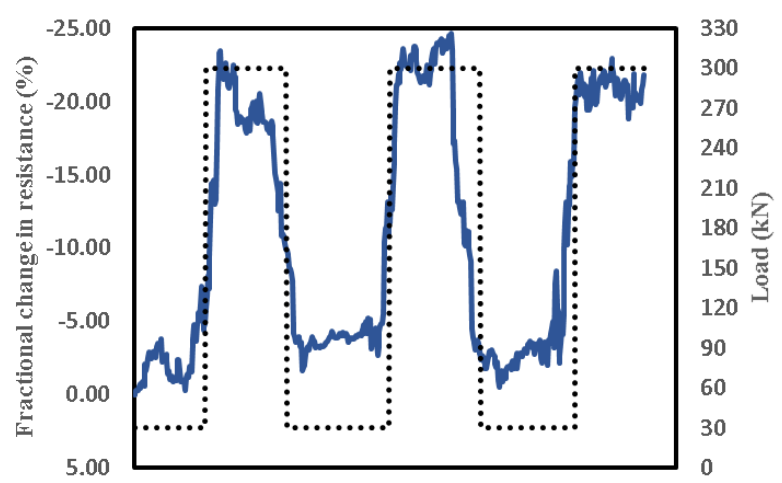

Fig. 7. Fractional change in electrical resistance (continuous line) under repeated loading (dot line) of $30 \mathrm{~mm}$ fiber length at maximum loading level of $300 \mathrm{kN}$ with applied voltage of $20 \mathrm{~V}$ and frequency of $50 \mathrm{~Hz}$.

\section{Conclusions}

The results of this paper illustrated the self-sensing behavior of steel fiber reinforced concrete. The selfsensing is evaluated by the measurement of the electrical resistance under compressive loading. The effect of fiber length, potential input, frequency, and level of loading on the self-sensing characteristics are reported. In general, results show that the self-sensing ability of steel fiber concrete is affected by the parameters mentioned above. In terms of fiber properties, high fiber length shows better self-sensing properties. From a point of view of testing configuration, the potential input $(10 \mathrm{~V}$ or $20 \mathrm{~V})$ and frequency $(50 \mathrm{~Hz}$ or $500 \mathrm{~Hz})$ significantly changes the self-sensing properties. The sensitivity of steel fiber reinforced concrete decreases significantly with decreasing the voltage. Meanwhile, the use of higher frequency induces poor repeatability of the results. The electrical resistance under the same load was not the same on different loading cycles. There is an increase of electrical resistance on the same load level for different loading cycles. The investigation also shows that an increase of the maximum load level from $150 \mathrm{kN}$ to 300 $\mathrm{kN}$ results in an increase of the self-sensing sensitivity from $12 \%$ to $24 \%$. It is concluded that the variable like fiber length, potential input value, frequency and loading 
level are influent factors on the self-sensing ability of steel fiber reinforced concrete. Within studied parameters it can be concluded that the optimum sensitivity is by using fiber length of $30 \mathrm{~mm}$ with potential input $20 \mathrm{~V}$ and frequency $50 \mathrm{~Hz}$. However, it is necessary to have further investigations using other variables such as variation of fiber volume, number of electrodes, distance between electrodes, to find an optimum self-sensing property of steel fiber reinforced concrete.

\section{References}

[1] P.-W. Chen, D. D. L. Chung, Compos. Part B Eng., 27, 11 (1996)

[2] D. D. L. Chung, J. Intell. Mater. Syst. Struct., 13, 599 (2002)

[3] S. Wen, D. D. L. Chung, Carbon, 45, 710 (2007)

[4] K. . Rosada, R. S, and P. C, Mater. Sci. Forums, 379 (2013)

[5] S. Wen, D. D. . Chung, Cem. Concr. Res., 31, 291(2001)

[6] S. Wen, D. D. L. Chung, Cem. Concr. Res., 31, 1515 (2001)

[7] D. D. L. Chung, Adv. Cem. Res., 16, 167(2004)
[8] F. Azhari, N. Banthia, Cem. Concr. Compos., 34, 866( 2012)

[9] B. Han, X. Yu, E. Kwon, Nanotechnology, 20, 445 ( 2009)

[10] D. Gao, M. Strum, Y. Mao, Smart Mater. Struct., vol. 18, 1(2009)

[11] R. Howser, H. Dhonde, Y. Mao, Smart Mater. Struct., 1 (2011)

[12] S. Dong, B. Han, J. Ou, Z. Li, L. Han, and X. Yu, Cem. Concr. Compos., 72, 48(2016)

[13] X. Luo, D. D. L. Chung, Cem. Concr. Res., 30, $323(2000)$

[14] S. Wen, D. D. L. Chung, Cem. Concr. Res., 32, 1429 (2002)

[15] B. Han, X. Yu, J. Ou, J. Mater. Sci., 45, 3714 (2010)

[16] F. Xuli, D. D. L. Chung, Cem. Concr. Res., 25, 1391(1995)

[17] D. D. L. Chung, Proc IMechE, 221, 509

[18] B. Han, K. Zhang, X. Yu, E. Kwon, J. Ou, Cem. Concr. Compos., 34, pp. 794 (2012)

[19] C. Bing, W. Keru, Y. Wu, Cem. Concr. Compos., 26, 291 (2004)

[20] B. Han, J. Ou, Sens. Actuators Phys., 138, 294 (2007). 